\title{
Os mexicanos-americanos e a nação americana Resposta ao professor Huntington
}

\author{
Edward Telles \\ Tradução de Alexandre Massella
}

A história clássica da assi milação americana narra a imigração européia aos Estados U nidos há um século e a absorção dos descendentes pela sociedade. Entre 1850 e 1930, esses imigrantes, principalmente alemães, irlandeses, italianos, poloneses e judeus, deixaram seus países em várias ondas para construir uma nova vida no N ovo M undo. Embora não tenham conseguido ascender na estrutura de classe, permanecendo nas camadas mais baixas, seus filhos enetos subiram na escada da mobilidadee setornaram "americanos comuns", isto é, pessoas de classe média, casadas com outros grupos étnicos e defala exclusivamenteinglesa. $N$ a terceira geração, a mai oria quase não se considera partedeum grupo "étnico". H á diferenças importantes entreesses grupos que não devem ser banalizadas, como muitas versões idealizadas da história o fazem, mas, em geral, essa éa história da assi milação.

Samuel P. H untington, professor da $\mathrm{H}$ arvard U niversity, sustenta que os atuais imigrantes apresentam uma trajetória bem diferente1. O s latinos, particularmente os mexicanos, afirma ele, estariam sobrecarregando as fronteiras e o mercado de trabalho americano, e não haveria a mesma assimilação de seus descendentes, aquela que no passado permitiu a incorporação dos imigrantes europeus. Segundo H untington, isso pode criar uma sociedade latina separada, com valores e cultura distintos, e não integrada à sociedade americana. Entretanto, suas conclusões são baseadas em pressupostos equivocados e em evidência superficial que contraria os

1. Samuel P. H untington é professor de Ciência Política na Universidade de $\mathrm{H}$ arvard eautor deW ho are we? The challenges to America'snational identity (2004). M eu artigo é uma resposta a uma pal estra dada pelo professor na Texas $A \& M$ University durante a U niversity $D$ istinguished Lecture Series, em 10 de outubro de 2005 (cf. H untington, 2005). Essa palestra se baseou no capítulo "Imigração mexicana ehispanização" de Who arewe? Reproduzo a seguir um resumo dafala de H untington, extraído da página ele- 
trônica da universidade (disponível em http://www.ta

mu.edu/provost/udls/ huntington.html): "0 11 de setembro despertou o patriotismo americano euma renovação da identidade americana. M as já há sinais de que esse despertar está arrefecendo. A América foi fundada por colonos britânicos que trouxeram consigo uma cultura distinta, incluindo características como a língua inglesa, valores protestantes, individualismo, religiosidade e respeito pela lei. As ondasdeimigrantesque chegaram depois aceitaram, gradualmente, esses val ores e assimilaram a cultura americana anglo-protestante. Recentemente, porém, a identidade nacional vem sendo corroída pelos problemasligados à assimilação de um grande número de imigrantes hispânicos, ao bilingüismo, ao multiculturalismo, à desvalorização da cidadania e à 'desnacionalização' das elitesamericanas'. H untington defende que precisamos reafirmar os valores centrais quenos fazem americanos. 0 queestáem jogo énada dados da ciência social contemporânea e as noções de mercado de trabaIho, cultura e assimilação.

Para começar, H untington prefere ignorar a vasta pesquisa científica a respeito do volume e do impacto da imigração legal e ilegal. Sua percepção da questão não difere muito daquela que predomina entre os que querem restringir a imigração ou entre os grupos de vigilância como o Arizona $\mathrm{M}$ inutemen. Certamente as percepções são importantes, mas, pelo menos para os cientistas, devem ser acompanhadas por uma análise rigorosa.

0 melhor trabalho acadêmico sobre o tema é a obra em dois volumes da A cademia N acional de Ciências, intitulada The immigration debate: studies on the economic, demographic, and fiscal effects of immigration (Smith and Edmonston, 1998). 0 estudo mostra, em primeiro lugar, que, mesmo quando a imigração legal ea ilegal são levadas em conta, osníveis atuais de imigração (em relação à população nativa) estão abaixo daqueles al cançados em qualquer fase durante o período 1850-1930. Em segundo lugar, o estudo aponta quea imigração ébenéfica à economia americana eaostrabal hadoresnativos, embora possa exercer um pequeno impacto negativo sobre os menos escolarizados. $\mathrm{O}$ estudo refuta o pressuposto de $\mathrm{H}$ untington de que os mercados de trabalho são instituições estáticas nas quais os imigrantes são um substituto barato para os trabalhadores nascidos nos Estados U nidos. Os mercados detrabalho são, sim, dinâmicose complexos, eosimigrantesmuitas vezes complementam a mão-de-obra nativa, preservando indústriase, assim, criando maisempregoseproporcionando aos consumidoresamericanos benseserviços de baixo custo. Em relação aos custosfiscais, el esinexistem no âmbito federal, mas estados com grande número de imigrantes gastam de forma desproporcional com a educação de seus filhos. M as isso pode ser um investimento necessário: a população americana está ficando mais velha, a fertilidadeestáabaixo do nível necessário para a reposi ção eo nível educacional cada vez mais elevado está alterando a natureza da força de trabalho. As pesquisas econômicas prevêem quea economia norte-americana preci saráde milhões de trabalhadores adicionais para manter o crescimento observado em décadas.

A possibilidade de um pequeno impacto negativo sobre os trabalhadores americanos com pouca qualificação é um motivo legítimo de preocupação. Todavia, o relatório da Academia N acional de Ciências, assim como outros estudos, apontam também que os efeitos do livre comércio são tão prejudiciais aos trabalhadores menos escolarizados quanto a concorrência dos imigrantes, e quetanto o livre comércio como a imigração beneficiam a 
grande maioria dos americanos. Para aqueles menos escolarizados, maiores investimentos em educação seriam meios mais eficazes para melhorar sua situação do que a restrição ou a interrupção da imigração.

\section{Controvérsias culturais}

As pessoas que, como H untington, propõem a restrição da imigração receiam, sobretudo, as chamadas diferenças culturais entre os hispânicos e o restante da sociedade americana. Para $\mathrm{H}$ untington, o problema é a "inferioridade cultural" (a discutível expressão moderna que substitui a de "inferioridade racial") dos novos imigrantes, e ele acredita que tais diferenças persistirão bem além da geração que imigrou. Esse parece ser um sentimento comum em um setor da população americana, mas, como mostrarei em seguida, não se sustenta. Para mencionar minhas próprias observações casuais, li várias entrevistas, em jornais e blogs, com os que propõem a restrição da imigração: muitos acreditam que o problema é menos a mãode-obra barata do que a suposta recusa à assimilação, já que os imigrantes estariam trazendo esposas e filhos, se recusando a falar inglês, criando comunidades ilegais de imigrantes, e assim por diante. Esses críticos se perguntam por que os americanos deveriam investir na educação dos filhos de imigrantes se estes jamais adotarão os valores ou a cultura americana.

Como a visão dos ativistas que pregam a restrição, os comentários de $\mathrm{H}$ untington a respeito das perspectivas de assimilação são mal informados. $0 \mathrm{~N}$ ew York Times de 7 de outubro de 2005 contém um artigo intitulado "San Antonio proudly lines up behind the military recruiter", apontando que, dos 41 batalhões de recrutamento do exército espal hados nos Estados U nidos, o de San Antonio foi o mais bem-sucedido. O ra, conhecendo San Antonio e a área circundante, é possível conjeturar que cerca da metade dos habitantes entre 18 e 25 anos tem ascendência mexicana. U ma porcentagem ainda maior de recrutas tem essa ascendência.

U m artigo de 1996 do American Journal of Political Science apresenta um levantamento nacional que aponta que os mexicanos-americanos, se jam bilíngües, sejam de língua predominantemente inglesa ou espanhola, são tão patriotas quanto os anglos-saxões de mesmo status socioeconômico, e às vezes até mais (cf. D e la G arza et al., 1996). Isto é, eles expressam a mesma paixão, ou até mais intensa, pelos Estados U nidos e orgulho em ser americano. Seria difícil reconciliar isso com a visão de que se está constituindo uma sociedade separada. 0 máximo que poderíamos dizer éque, se menos do que nossa identidade nacional. 
os mexicanos-americanos têm valores diferentes dos americanos, o patriotismo americano mais intenso é um deles. Pelo menos para os mexicanosamericanos, a identidade étnica não representa um desafio à identidade nacional, mas são compatíveis.

$\mathrm{O}$ entendimento de H untington a respeito daquilo queosimigrantes devem assimilar também apresenta problemas. Ele parece endossar as idéias de assimilação do início do século XX, queenfatizavam um núcleo branco, protestante e anglo-saxão. Entretanto, esse pressuposto de uma essência WASP [W hite, Anglo-Saxan and Protestant] na cultura americana deu lugar à idéia deum caldo decultura por volta dosanos de 1960, senão antes, emaisrecentemente o conceito de um modo de vida americano em mudança se tornou corrente. A visão moderna de assimilação reconhece o caráter dinâmico, e não estático, da cultura americana, que historicamente foi influenciada por correntes externas, como a do Iluminismo francês, epelas contribuições dos sucessivos grupos de imigrantes. Estas últimas são mais evidentes na culinária que os imigrantes trouxeram consigo, como a pizza e os tacos, alimentos hoje aceitos como parte da cozinha americana. A "cultura americana" em constante mudança, que incluiu os descendentes dos austeros puritanos WASP, incorporou nos anos de 1880 as noções dos imigrantes al emães a respeito do lazer eos estilos musicaise de dança dos africanos e seus descendentes. A assimilação éuma via de duas mãos: os imigrantes eseus descendentes setornam partedo modo de vida predominanteeeste, por sua vez, sofremudanças. $0 \mathrm{~s}$ americanos ou britânicos de hoje não reconheceriam a cultura WASP dos séculos XVI eXVII como sua própria cultura.

O s modernos conceitos de assimilação reconhecem também que os imigrantes e seus descendentes assimilam, ainda que não busquem isso de formaativa. Emboramuitosimigrantesdesejem preservar, nanovaterra, aspectos de sua cultura e modo de vida nativo, muitos se adaptam, consciente ou inconscientemente, ao viver o cotidiano eao tentar tornar-se parte da classe média. N esse processo, eles devem, em geral, aprender inglês, e a ascensão implica conseguir um emprego em uma ocupação bem remunerada, naqual provavelmente terão muitos colegas não-étnicos. A ascensão social significa também, muitas vezes, a mudança para um bai rro de classemédia, provavelmentedominado por pessoas quenão são partedo grupo étnico do imigrante. É difícil evitar a influência da proximidade com colegas de trabalho e vizinhos não-étnicos, já queé preciso interagir, conversar em inglês eestabelecer bases comuns de todo o tipo. As mudanças econômicas e residenciais moldam as escolhas políticas, religiosas eaté matrimoniais dos imigrantes. 
Por fim, os novos conceitos relativos à assimilação incorporam a idéia de que 0 ritmo desta pode variar entre os diversos grupos imigrantes, algo observado também no passado. Entre os fatores que aceleram ou retardam a assimilação, temos: as oportunidades econômicas que aguardam certos grupos de imigrantes; 0 capital humano que os imigrantes trazem consigo, especialmente o nível de escolaridade; a acolhida dada a eles pelos governos federal e estaduais, que costumam dar generosa assistência a certos refugiados e tratar outros imigrantes como ilegais, barrando-Ihes 0 acesso a serviços públicos de saúde e educação. Constrangimentos sociais como a raça também afetam o ritmo da assimilação, questão a que retornarei.

Assimilação mexicana: tendências entre gerações

H ouve duas grandes ondas de imigração na história norte-americana. A primeira, entre 1850 e 1930, foi em grande parte européia. A segunda começou em 1965, após uma mudança na lei de imigração, que aumentou a quota de entradas, deu preferência a pessoas com habilidades profissionaise anulou qualquer restrição relativa à origem nacional. 0 s novos imigrantes quese beneficiaram dessa oportunidade vieram principal menteda América Latina edaÁsia, e os mexicanos constituíram o maior grupo. M uitos desses recém-chegados, especialmente asiáticos, eram profissionais com níveis de capital humano que ultrapassavam os do americano médio. 0 s mexicanos, por outro lado, assim como os imigrantes da América Central, os dominicanos ealguns grupos do Leste asiático, vieram com níveis bem reduzidos de capital humano, como a maioria dos imigrantes europeus da primeira onda.

O s sociólogos debatem a respeito de como a segunda onda será incorporada, especialmente no caso dos imigrantes com baixo nível de capital humano. Esses grupos serão assimilados na segunda ou terceira geração, como ocorreu antes com os europeus? Como os descendentes da nova imigração mexicana se integrarão na estrutura social americana? 0 sociólogo Alejandro Portes e seus colegas prevêem um futuro de assimilação "segmentada", em que al guns grupos, particularmente os que chegam com alto nível de capital humano, se sai rão bem, ao passo que outros, como os mexicanos, serão incorporados em patamares inferiores (cf. Portes e Zhou, 1993; Portes e Rumbaut, 2001). O utros especialistas, como os sociólogos Richard Alba e Victor N ee (2003), são mais otimistas. Eles prevêem que a assimilação será similar à que se deu com os europeus. Empiricamente não sabemos ao certo, já que os filhos dessa nova onda ainda são jovens 
demais para nos proporcionar respostas definidas. $M$ as temos alguns indicadores. A melhor evidência pode ser obtida examinando-se as experiências dos descendentes do considerável número de imigrantes mexicanos e de mexicanos-americanos que residiu nos Estados U nidos antes da segunda onda.

D iferentemente da imigração proveniente de qualquer outro país, a imigração mexicana fez partedas duas ondas econtinuou no período entreelas. Além disso, a imigração mexicana no século XX se somou a uma população de cerca de 420 mil mexicanos-americanos que já estavam estabelecidos e foram computados pelo censo de 1900. É claro que muitas dessas pessoas eram descendentes de mexicanos cuja cidadania mudou não como resultado da imigração, mas em razão da conquista americana do M éxico em 1848. D urante os anos de 1910 e1920, período queinclui a R evolução M exicana, cercade $10 \%$ da população mexicana partiu para os Estados U nidos. Com a Grande D epressão, muitos imigrantes mexicanos, assim como seus filhos nascidos nos Estados U nidos, foram "repatriados" nos anos de 1930, pois seu trabal ho não era mais necessário. M as a imigração mexicana prosseguiu, especialmente por meio do programa do trabal hador convidado, no período entre 1942 e 1964, e continuou aumentando depois de 1965.

Participei de um amplo levantamento longitudinal com a professora Vilma 0 rtiz, também da U CLA, queanalisa as experiências de quatro gerações de mexicanos-americanos entre 1965 e2000. N ossa equipe de pesquisa, com o generoso financiamento do $\mathrm{N}$ ational Institute of $\mathrm{C}$ hild and $\mathrm{H}$ uman D evelopment, tenta localizar mexicanos-americanos que fizeram parte, em 1965, de um estudo por amostragem al eatória realizado no condado de LoS Angeles, na Califórnia, ena cidade de San Antonio, no Texas. U ma equipe de pesquisa interdisciplinar daU CLA elaborou um volumecom dados desse levantamento, intitulado The M exican American people (Grebler et al., 1970). Procuramos conversar novamente com os entrevistados que tinham menos de 50 anos no estudo original, onde quer que estivessem vivendo, e conseguimos localizar e entrevistar cerca de dois terços deles, além de uma amostragem de seus filhos. N o total, realizamos 1.500 entrevistas em nosso levantamento, ao qual me referirei como levantamento 2000, já que foi realizado entre 1998 e 2000.

Ao tentarmos determinar se esses mexicanos-americanos foram assimilados, e como, elaboramos perguntas sobre vários indicadores normalmente associados à assimilação ou à incorporação na sociedade norte-americana. O sindicadoresmaisimportantes são escolaridade, proficiência na língua, 
intercasamento, filiação religiosa e política. Examinamos as diferenças entre as respostas dos entrevistados em 1965 e as de seus filhos em 2000, observando três gerações distintas em cada caso.

Linguagem e educação

A Figura 1 mostra, com base em nossos dados, tendências ao longo de gerações no aspecto escolaridade e proficiência no espanhol. Empregamos um modelo estatístico que controla variáveis como idade, sexo, educação dos pais e se os entrevistados tinham ou não pais casados com outros grupos étnicos.

FIGURA 1

Tendências relativas à proficiência lingüística e à escolaridade

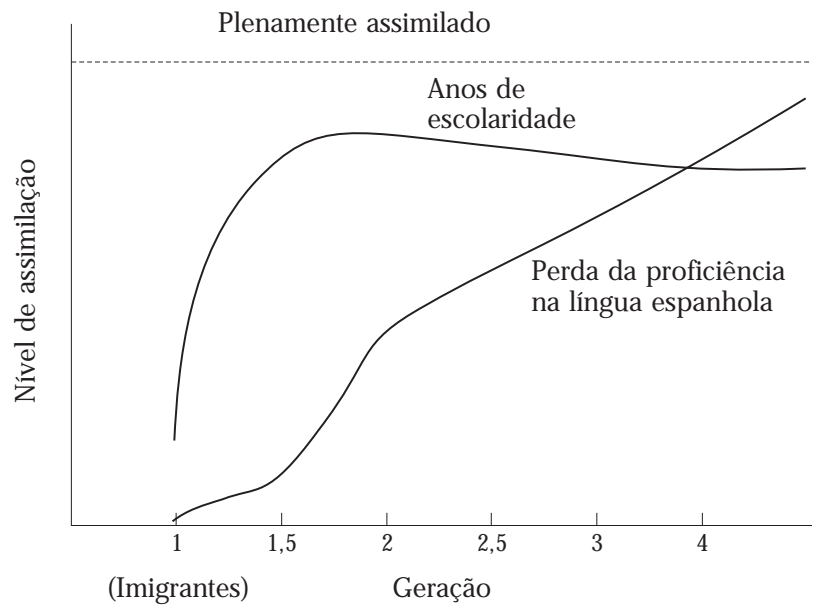

Em relação à língua, $\mathrm{H}$ untington curiosamente lamenta que os mexicanos-americanos não abandonaram o espanhol, ainda que admita, de forma correta, que os filhos nascidos nos Estados U nidos aprenderam o inglês na segunda geração. N ossos dados mostram que os mexicanos-americanos conservam a língua espanhola por mais tempo do que outros grupos latinos norte-americanos, mas não a conservam para sempre. Eles acabam por perder a língua natal, algo consistente com a assimilação plena na dimensão lingüística. D e fato, como a figura mostra, a perda da proficiência no espanhol pelos descendentes dos imigrantes mexicanos exibe uma tendência linear de assimilação. $\mathrm{N}$ a quarta geração, somente $5 \%$ falam espanhol com os filhos de quinta geração. Abordarei na seqüência o tema do valor da conservação da língua espanhola. 
0 maior problema na incorporação dos mexicanos-americanos não está na língua, mas na educação. Comparados aos brancos, eles mostram um persistente atraso nos níveis médios de educação e na mobilidade socioeconômica que advém da escolaridade. $\mathrm{Na}$ média, os imigrantes mexicanos que chegaram aqui na infância ou na adolescência (a chamada geração 1.5) e os filhos de imigrantes nascidos nos Estados U nidos (a segunda geração) alcançam os níveis mais al tos de educação, embora estes ainda estejam abaixo dos da população "branca não-hispânica". A experiência é similar à dos imigrantes italianos, na qual a segunda geração foi bem além da primeira, mas não atingiu os níveis educacionais da população americana geral. Entretanto, os italianos da terceira geração continuaram a ascender e alcançaram o nível médio educacional dos brancos, ao passo que a terceira e a quarta gerações de mexicanos-americanos mostram resultados educacionais piores do que os da segunda geração. Assim, para os eles, a trajetória tradicional de contínua ascensão e assimilação educacional é revertida de pois das conquistas da primeira e segunda gerações. Sua educação fica aquém da assimilação plena e atinge o ápice na segunda geração.

Por queisso ocorre? U m fator podeser o tradicional otimismo imigrante: tipicamente, os novosimigrantes chegam aos Estados U nidos determinados a fazer a América e sabem bem os avanços obtidos em comparação com a vida que levavam antes. A poiados por comunidades de imigrantes coesas, eles se empenham para ascender e estimulam a segunda geração a fazer 0 mesmo. $N$ a terceira geração, porém, o otimismo de muitos jovens de origem mexicanajá não éo mesmo, poiseles sentem quenão são valorizadosna escola ou na sociedade mais ampla. Embora al guns mexicanos-americanos se saiam bem e consigam entrar em universidades de elite, como a Texas $A \& M$, a U CLA eaté $H$ arvard, a maioria desses jovens recebe uma educação limitada, tanto quantitativa como qual itativamente. U m crescentecorpo de pesquisa apóia essa análise desanimadora.

0 problemanão éa relutância dos latinosem adotar os valores ea cultura americanos, mas o fracasso das instituições sociais, particularmente das escolas públicas, em incorporar esses indivíduos de forma eficaz, tal como foi feito com os descendentes dos imigrantes europeus. A educação éa área em quetodos gostariam dever uma maior assimilação, masisso não ocorreu. A adaptação mais notável se deu na dimensão da perda da língua étnica, o que é lamentável, pois sua conservação seria desejável em uma sociedade cada vez mais globalizada. Ademais, as evidências da ciência social mostram que isso não implica o enfraquecimento da identidade nacional. 
Intercasamento

A Figura 2 mostra as taxas de intercasamento para os entrevistados originais e seus filhos, decompondo cada uma dessas categorias em gerações. O s entrevistados originais são divididos em: primeira geração, imigrantes nascidos no M éxico; segunda geração, pessoas nascidas nos Estados U nidos de pais imigrantes; terceira geração, pessoas nascidas nos Estados U nidos de pais também nascidos aí. 0 s filhos dos entrevistados originais, quase todos nascidos nos Estados U nidos, são divididos em segunda, terceira e quarta gerações. As mesmas divisões são usadas nas Figuras 3 e 4.

A Figura 2 revela claros padrões de assimilação por meio do casamento com outros grupos étnicos, tanto ao longo do tempo (colunas) como ao longo das gerações (linhas). Entre os entrevistados originais, as taxas de intercasamento vão de $9 \%$ na geração imigrantepara $17 \%$ naterceira geração. O sfilhos dos entrevistados originais, de segunda, terceira e quarta gerações, apresentam uma taxa de intercasamento que varia de $21 \%$ a 29\%. A título de comparação: dados recentes apontam uma taxa deintercasamento decerca de $60 \%$ para as pessoas de ascen dência irlandesa ou italiana (cf. Lieberson eWaters, 1988, p. 173) e de somente $1 \%$ para os afro-americanos.

FIGURA 2

Tendências relativas ao intercasamento: porcentagem dos que se casaram fora de seu grupo étnico

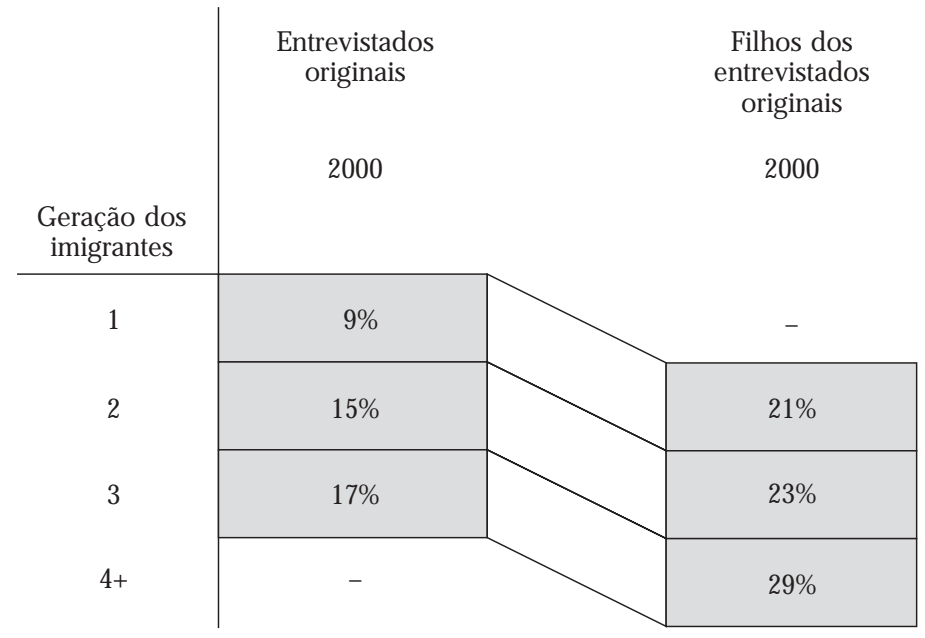


Filiação religiosa e política

O ritmo da aculturação religiosa ésurpreendente(Fig. 3). H á um declínio uniforme e acentuado do catolicismo ao longo das gerações. $\mathrm{N}$ a quarta ge ração, apenas metade dos mexicanos-americanos é católica. Refletindo a tendência norte-americana em geral, a mai oria dos que abandonam o catolicismo (eoutras religiões estabelecidas) seconvertepara denominações evangélicas ou protestantes fundamentalistas.

H á também sinais de assimilação na filiação política (Fig. 4). Atualmente os mexicanos-americanos são menos leais ao Partido D emocrata. N osso estudo comparou o voto na eleição presidencial de 1964 (Johnson versus G oldwater) com a de 1996 (Clinton versusD ole). Em 1964, a grandemaioria dos mexicanos-americanos de Los Angeles eSan Antonio votou no Partido D emocrata, mas em 1996 somente três quartos de seus filhos fizeram o mesmo, embora uma alta porcentagem dos entrevistados originais continuasse votando nos democratas. A leal dadeao Partido D emocrataéde $90 \%$ ou mais entre negros e judeus. Esse padrão de voto étnico reflete, em certa medida, a tendência nacional, mas não inteiramente: em 1964, Johnson venceu com $63 \%$ dos votos, ao passo que Clinton venceu com apenas $49 \%$ em 1996, as duas taxas bem abaixo dos níveis de voto nos democratas entre os mexicanos-americanos.

FIGURA 3

Tendências relativas à filiação religi osa: porcentagem dos que se identificam como católicos

\begin{tabular}{|c|c|c|c|}
\hline \multirow{2}{*}{$\begin{array}{l}\text { Geração dos } \\
\text { imigrantes }\end{array}$} & \multicolumn{2}{|c|}{ Entrevistados originais } & $\begin{array}{l}\text { Filhos dos } \\
\text { entrevistados }\end{array}$ \\
\hline & 1965 & 2000 & 2000 \\
\hline 1 & $91 \%$ & $81 \%$ & - \\
\hline 2 & $90 \%$ & $82 \%$ & $75 \%$ \\
\hline 3 & $86 \%$ & $84 \%$ & $68 \%$ \\
\hline $4+$ & - & - & $57 \%$ \\
\hline
\end{tabular}


FIGURA 4

Tendências relativas à filiação política: porcentagem dos que votaram no Partido D emocrata nas eleições presidenciais de 1964 e 1996

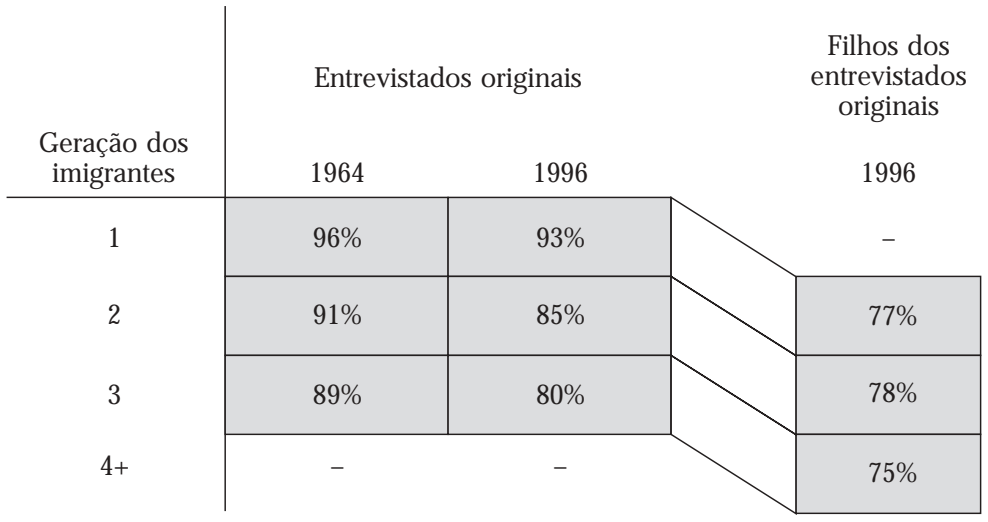

Fatores que moldam a experiência mexicana-americana

N ossos dados mostram, assim, uma constante assimilação nos âmbitos de língua, intercasamento, religião e política, talvez lenta se comparada com a de outros grupos, mas que de qualquer forma avança. A educação e a mobilidade social são outra questão. $\mathrm{N}$ a média, uma resistente persistência do baixo nível de escolaridade concentrou os mexicanos-americanos nas posições da classe trabalhadora. Por que sua incorporação na sociedadenorte-americana diferiu nesse aspecto da experiência de assimilação dos imigrantes europeus?

Em primeiro lugar, o contexto da imigração mexicanaéúnico na história dosEstados U nidos. 0 influxo depessoas dessepaís prosseguiu durantepelo menos cem anos, estimulado pelo longo envolvimento da economia norteamericana com os trabal hadores mexicanos. Trata-se de uma dura realidade que caracteriza a experiência dessa população equenão mudará facilmente. Em virtude das necessidades de mão-de-obra, da disparidade de desenvolvimento entre os dois países e da fronteira comum de 2 mil milhas, éimprovável que os Estados U nidos testemunhem o súbito fim da imigração mexicana em larga escala, como ocorreu com a imigração européia.

Em segundo lugar, a persistência do baixo status parece refletir um processo de racialização, isto é, de atribuição social de características indesejáveis a um povo com uma ascendência ou um fenótipo particular (cf. Feagin, 2006), bem como as conseqüências institucionais dessa exclusão. 0 tratamento dado a mexicanos e a mexicanos-americanos nos Estados Unidos 
está enraizado na diferença, na hierarquia racial e na história de colonização e conquista. H istoricamente os mexicanos foram tratados como uma força de trabalho desejável, mas cuja cultura, língua e biologia seriam inferiorese indesejáveis. A idéia ainda preval ece hoje, como atesta o trabal ho do professor $\mathrm{H}$ untington. Embora os primeiros imigrantes irlandeses e italianos tenham sido tratados como indesejáveis, seus filhos se tornaram socialmente "brancos" e, assim, se qualificaram para receber os privilégios e benefícios da classe mais alta. Infelizmente, os mexicanos não puderam seguir a mesma trajetória branca.

N os anos de 1830 e 1840, muitos líderes americanos sustentaram, explicitamente, que os mexicanos (e outros povos de pele escura) eram incapazes de autodeterminação. $A$ idéia do $D$ estino $M$ anifesto reivindicava a expansão dos EstadosU nidos rumo ao sul, para que os brancosamericanos, empreendedores e intelectualmente superiores, desenvolvessem essas terras ricas. Embora os Estados U nidos estivessem ansiosos para anexar o território mexicano, não demonstravam o mesmo entusiasmo em relação aos mexicanos que viriam com a terra. U m senador de M ichigan parecia falar em nome da maioria do Congresso quando argumentou que a anexação não deveria envolver mais do que os territórios pouco povoados do norte do M éxico: "N ão queremos os mexicanos como cidadãos" (citado em Gutiérrez, 1995, p. 16). Esse sentimento refletia a disseminada visão de que os mexicanos, na qualidade de uma "raça em parte de cor", eram estranhos, "inassimiláveis" eintelectualmente inferiores (cf. M ontejano, 1987, p. 181; Gutiérrez, 1995, p. 16).

Cem anos depois, quando os filhos dos imigrantes europeus deixaram de ser étnicos ese tornaram indistinguíveis dos americanos brancos, os mexicanos ainda eram classificados em uma categoria racial própria no censo de 1930. Isso refletia as experiências de segregação em que viviam: mercados de trabal ho segmentados, segregação administrativa em relação aos brancos ou anglo-saxões em muitas localidades, pagamento de impostos per capita no Texas até 1966 e taxas de linchamento que se aproximavam da dos afroamericanos. É certo que a classificação racial e a discriminação foram mais complexas e sutis no caso dos mexicanos-americanos do que no dos negros, e sua rispidez e amplitude variou bastante segundo o período histórico, a área eosindivíduos. N ão obstante, a discriminação continua. Ao enfatizar 0 "problema mexicano", os defensores da restrição à imigração estão pensando não só nos imigrantes mexicanos, mas também em seus descendentes supostamente inassimiláveis. 
U m terceiro fator da experiência dos mexicanos-americanos é que as escolas públicas voltadas às suas comunidades, localizadas principal mente nas cidades centraisenasáreas rurais, estão entreas piores do país. Além disso, os mexicanos-americanos em escolas integradas foram desproporcionalmente inseridos em currículos de baixo nível. U ma persistente e alta taxa de abandono escolar faz desteo grupo com o menor nível deescolaridadedo país. De fato, é possível afirmar quea escola foi o principal fator institucional responsável pelo baixo status dos mexicanos nascidos nos Estados U nidos.

Para os descendentes da atual onda de imigrantes mexicanos, esses padrões continuarão a prevalecer. $M$ as há três fatores que provavelmente afetarão, de diversas maneiras, a assimilação no futuro.

Em primeiro lugar, a estrutura da economia americana está mudando, al go que provavelmente reduzirá ainda mais as perspectivas de assimilação dos atuais descendentes. D esde o final dos anos de 1970, a escolaridade é cada vez mais um fator decisivo para o êxito econômico na sociedade americana. Aumentou o salário dos que possuem diploma universitário e diminuiu o dos que têm apenas o nível secundário, fato que levou à crescente polarização da renda. Com o declínio da indústria pesada e a conseqüente redução dos postos de trabalho manual bem remunerados para os menos escolarizados, aumentaram os rendimentos das pessoas de nível universitário, dando à economia uma forma de ampulheta. 0 s trabal hos intermediários, que permitiram a ascensão dos primeiros imigrantes e seus descendentes, estão desaparecendo gradualmente. A educação énecessária para superar o fosso.

Em segundo lugar, a condição de ilegal de muitos imigrantes de hoje tende a dificultar a mobilidade social de seus descendentes. Os filhos dos ilegais são prejudicados quando privados do acesso aos serviços públicos disponíveis a cidadãos eimigrantes legais, como seguro desemprego ebenefícios que protegem contra as adversidades econômicas.

Em terceiro lugar, a globalização pode acelerar a assimilação dos futuros imigrantes mexicanos e seus descendentes. A globalização torna 0 aprendizado do inglês acessível na sociedade de onde veio o imigrante. Bem antes de chegar nos Estados U nidos, muitos já se familiarizaram com a língua inglesa e com a cultura americana por meio da televisão ou da influência dos imigrantes que retornaram. Como apontou Huntington em 0 choque das civilizações (1997), o M éxico e a América Latina estão se deslocando na direção do "bloco da civilização americana", razão pela qual a cultura americana não é inteiramente estranha aos imigrantes mexica- 
nos. N esse ponto concordo com H untington, embora essa afirmação contradiga sua idéia mais recente de que haveria um abismo cultural entre mexicanos e americanos.

Escolhas políticas

0 que fazer em relação à imigração? As atuais políticas são contraditórias. D ependemos dos imigrantes, mas, ao mesmo tempo, dizemos a eles que devem ir embora. As contradições são particularmente gritantes em relação à imigração i ilegal. 0 s imigrantes ilegais recebem na C alifórnia facilidades para estudar na universidade, mas não podem secandidatar a financiamento educativo federal. Eles podem comprar carro e fazer seu seguro, mas, na maioria dos estados, não podem tirar carta de habilitação. Podem procurar emprego, freqüentemente em agências federais, mas não podem trabal har legalmente. As contradições estendem-se a nossas relações com 0 M éxico, vizinho esegundo maior parceiro comercial, mas constantealvo de críticas (cf. Gorman e D elson, 2005).

Temos milhões de residentes que, segundo a lei, não deveriam estar aqui, mas que, economicamente, são necessários ao país como fonte de mão-deobra barata. 0 súbito fim da imigração mexicana seria desastroso para muitos setores da economia americana. Assim como a Lei Seca denegou a dependência americana ao álcool, nossa atual política de imigração refletea denegação de outro tipo de dependência.

É possível, porém, elaborar uma solução que beneficiaria a quase todos. U m programa realista de quotas de imigração que satisfaria as necessi dades de mão-de-obra seria certamente mais eficaz do que os esforços de fechar as fronteiras, al go quena prática não funcionaeserveapenas para gerar antagonismos com o M éxico. Esseprograma realista permitiria um maior controle da imigração e das fronteiras. Seria preciso associá-lo a reformas que dariam aos imigrantes a possi bilidade de escolher entre o caminho para a cidadania ou o retorno ao país de origem. A reforma relativa à imigração entrou recentementena agenda política, eas idéias propostas devem ser avaliadas ediscutidas deforma ponderada.

A intervenção de H untington não contribui para esse tipo de reflexão. Autor de obras anteriores importantes, ao abordar o tema da imigração ele parece ter esquecido seu treinamento sistemático e imparcial de cientista social. Receio queas afirmações de H untington, proferidas por um eminente professor de $\mathrm{H}$ arvard, encorajem os apavorados americanos pós-11 de 
setembro a acreditar, de forma equivocada, que os mexicanos constituam um desafio a seu modo de vida. $N$ ada poderia estar mais longe da verdade.

Em primeiro lugar, precisamos de um debate bem informado sobre a quantidade e o tipo de imigração que o país deveria permitir. N esse ponto, concordo com H untington: "Em nossa sociedade, o pluralismo ea moderação podem ser incentivados". Embora esteja ganhando corpo a opinião contrária à imigração, isso parece ser, em grande parte, uma resposta ao problema dos ilegais. A própria palavra evoca o espectro da criminalidade ea falta de controle. M as o fluxo de imigrantes ilegais é, essencialmente, um problema criado pelo ultrapassado sistema de vistos, que não satisfaz a crescente necessi dade de força de trabal ho do país. A reforma da imigração precisa admitir esse fato básico.

Em segundo lugar, para que a assimilação seja bem-sucedida, precisamos enfatizar as oportunidades e não simplesmente pregar os valores americanos. A professora M ary Waters (1990; 1999), da U niversidade de H arvard, estudou a antiga e a nova imigração, comparando a incorporação dos primeiros imigrantes europeus e de seus descendentes com a experiência dos atuais imigrantes. Ela descobriu que as forças propulsoras da americanização das primeiras ondas de imigração não foram as

[...] lições cívicas que eles recebiam na escola pública, mas a recompensa econômica desfrutada pelos descendentes dos imigrantes europeus [...]. À luz dessas descobertas, nossa sociedade não deveria limitar-se a perguntar como estruturar a política de imigração ou como encorajar os imigrantes a adotar nossa cultura cívica e se tornar americanos (Waters, 1999, p. 332).

Em vez disso, afirma Waters, a sociedade deveria se perguntar:

0 que podemos fazer em relação às desigualdades nas condições de vida americana, que muitas vezes significam que se tornar um negro americano ou um mexicano-americano leva a um futuro menos brilhante do que permanecer um imigrante?" (Idem, ibidem).

Em terceiro lugar, embora os mexicanos-americanos estejam assimilando a cultura, devemos nos perguntar se a assimilação incondicional e, em particular, a perda da língua nativa é realmente o que queremos. $N$ ão seria mais valioso o pluralismo cultural e lingüístico? Ser bilíngüe é certamente vantajoso para o indivíduo. Sabemos que o aprendizado de duas ou mais 
línguas durante a infância aprimora a capacidade cognitiva e há evidência de que crianças bilíngües apresentam um melhor desempenho escolar, com níveis mais el evados de auto-estima e taxas menores de depressão. A sociedade também se beneficia. A evidência sugerefortemente que uma população multilíngüe incrementará a competitividade americana e as relações internacionais, sem fragmentar a unidade doméstica. No longo prazo, 0 êxito da M iami cubana corre perigo, já que muitos cubanos americanos são incapazes de se comunicar com a clientela de língua espanhola, comunicação que ajudou a fazer dela uma cidade verdadeiramenteglobal. D esde o 11 de setembro, o governo americano tenta desesperadamente recrutar tradutores de várias línguas: a assi milação lingüística quase total dos árabes-americanos significa que não há americanos suficientes com árabe fluente que poderiam qualificar-se também para receber o certificado de segurança.

M uitos líderes mexicanos-americanos, assim como váriosamericanos, de fendem uma sociedade etnicamente diversa. Sistemas viáveis de pluralismo étnico existem em sociedades como Bélgica eSuíça. Por quenão nos Estados U nidos? É certo que fizemos al gumas tentativas de educação bilíngüe e de preservação da língua étnica, mas, aparentemente, se destinaram mais a facilitar a americanização e o aprendizado do inglês pelos imigrantes do que a preservar ou ensinar outras línguas que não a inglesa. A despeito dos anseios dos multiculturalistas, a assimilação está ocorrendo. Por outro lado, a persistência em muitos mexicanos-americanos de terceira e quarta gerações de alguma proficiência em espanhol éimpressionante à luz das intensas forças de americanização. D everíamos trabalhar para preservar e fortalecer essa proficiência lingüística, mantendo o espanhol dos mexicanos-americanos e assegurando que todas as crianças de língua inglesa nos Estados U nidos aprendam espanhol ou uma segunda língua.

Em vez defazer dosmexicanosum fácil bodeexpiatório paraumasériede problemas americanos, seria preciso avançar na direção de uma "verdadeira democracia participativa", como enfatiza D avid G utiérrez. 0 próprio H untington en dossa essa idéia. 0 smembros dessa democracia deverão "reconhecer a intrincada heterogeneidadeétnica de sua soci edade eaprender a aceitar e lidar de forma construtiva com as conseqüências políticas disso" (G utiérrez, 1995, p. 216). 


\section{Referências Bibliográficas}

Alba, Richard D. \& NeE Victor. (2003), Remaking the American mainstream: assimilation and contemporary immigration. C ambridge, M A, H arvard U niversity Press.

De la Garza, Rodolfo 0 .; Falcon, Angelo \& Garcia, Chris. (1996), “Will the real americans please stand up: Anglo and M exican-American support of core American political values". American Journal of Political Science, 40 (2): 335-351.

FEAGIN, Joe R. (2006). Systemic racism: a theory of opression. N ova York, Routledge.

Gorman , Anna \& Delson, Jennifer. (2005), "Policies on illegal immigrants at O dds". Los Angeles Times, 27 nov.

Grebler, Leo; M oore, Joan W. \& Guzman, Ralph C. (1970), The M exican-American people: the nation's second largest minority. N ova York, Free Press.

GutiérRez, D avid. (1995), Wallsand mi rrors: M exican Americans, M exican immigrants, and the politics of ethnicity. Berkeley, University of California Press.

H untington, Samuel P. (1997), The clash of civilizations and the remaking of world order. N ova York, Simon and Schuster.

. (2004), W ho are we? T he challenges to America's national identity. N ova York, Simon and Schuster.

. (2005), "American national identity: changes and challenges in the $21^{\text {st }}$

C entury". Trabalho apresentado na U niversity D istinguished Lecture Series, Texas A\& M University, College Station, 10 out.

Lieberson, Stanley \& W aters, M ary. (1988), From many strands: ethnic and racial groups in contemporary America. N ova York, Russell Sage Foundation.

M ontejan O, D avid. (1987). Anglosand M exicans in the making of Texas, 1936-1986. Austin, University of Texas Press.

Portes, Alejandro \& Rumbaut, Rubén. (2001), Legacies: the story of the immigrant second generation. Berkeley, U niversity of California Press.

Portes, Alejandro \& Zhou, M in. (1993), "The new second generation: segmented assimilation and its variants". Annals of the American Academy of Political and Social Science, 530: 74-96.

Sмiтh, James P. \& Edmonston, Barry. (1998), The immigration debate: studies on the economic, demographic, and fiscal effects of immigration. Washington, D.C., $\mathrm{N}$ ational Academy Press.

W aters, M ary C. (1990), Ethnic options: choosing identities in America. Berkeley, U niversity of California Press.

. (1999), Black identities: West Indian immigrant dreams and American realities. N ova York, Russel Sage Foundation. 


\section{Resumo}

Osmexicanos-americanose a nação americana: resposta ao professor Huntington

Este artigo baseia-se em uma palestra dada na Texas A\& M U niversity em 10 de dezembro de 2005, em resposta a uma palestra anterior do professor Samuel P. H untington. O s dados obtidos pela ciência social são usados para analisar a tese de H untington de que os mexicanos estão sobrecarregando as fronteiras americanas. 0 artigo analisa ainda a evidência de que os mexicanos-americanos estão sendo assimilados culturalmente, mas, em termos econômicos, não são tão bem-sucedidos quanto os descendentes dos primeiros imigrantes europeus; e examina os fatores que diferenciam, e provavelmente continuarão a fazêlo, a trajetória de incorporação dos mexicanos-americanos. Por fim, recomenda que a opinião pública americana e os políticos façam opções fundamentadas a respeito dos níveis desejáveis de imigração e das pessoas que devem ser aceitas, aperfeiçoem por meio da educação as oportunidades econômicas dos imigrantes e fomentem um futuro multilinguístico e multiétnico para o país.

Palavras-chave: Estados U nidos; M exicanos-americanos; Integração social; I migração.

Edward E. Telleséprofessor de Sociologia na Universidade da Califórnia, LosAngeles, re cebeu o D istinguished Scholarly Publication Award eo 0 tisD udley Duncan Award da American Sociological Association por seu livro sobre raças no Brasil. Seu próximo livro, escrito com Vilma O rtiz, analisa a mudança intergeracional entre os mexicanos-americanos com base em levantamentos por amostragem al eatória realizados em Los Angeles e San Antonio em 1965 e 2000. E-mail: telles@ soc.ucla.edu.

\section{Abstract}

Mexican-Americans and the American nation: a response to professor Huntington

This essay is based on a talk I delivered at Texas A\& M U niversity on D ecember 10, 2005, in response to an earlier lecture at the university by Professor Samuel P. H untington. It relies on social science evidence to first address $\mathrm{H}$ untington's contention that M exicans are overwhelming American borders. It then turns to evidence that M exican Americans are in fact assimilating culturally but still have been less economically successful than the descendants of earlier European immigrants. The essay examines factors that have differentiated the M exican American trajectory of incorporation and are likely to continue to do so. Finally, it calls for the American public and policy makers to make well-informed choices about what levels of immigration are desirable and who should be admitted, to improve immigrants' economic opportunities through education, and to embrace a multilingual and multiethnic future for the country.

Keywords: United States; M exican-americans; Social integration; Immigration. 